point came home to him. As it happens his back pain did not recur although the epidural infusion was taken down. He was reconciled to his daughter who was seen pushing him round the hospital in a wheelchair. Why did the pain not recur? I do not know. Pain is not just a pure sensation, but one that comes, as it were with a meaning attributed from the beginning. Physical interruption of the sensation by an anaesthetic drug can ease the pain, but so can re-attribution of a different meaning. This pain in his mind had something to do with his rift with his daughter. Maybe, with the rift healed, the pain was less of an overwhelming threat. (Examples in daily practice are less dramatic, but we have all seen patients after a heart attack who interpret every ache in their chest which they would previously have ignored, as angina. They will respond to careful listening and reassurance that these sensations have no sinister meaning, but are normal.)

Our view of society will also have an effect on the sort of doctor we strive to be; on the one hand, a doctor who gets involved in the local community, a Doctor Finlay, or at the other extreme, a bureaucratic, Stakhanovite ticker of QOF boxes. Finally, how we view society will have an effect on how keen we are to engage with politics at all levels. If man's very self is embedded in society, is the striving for social justice integral to the role of the doctor?

\section{Gervase Vernon}

\section{REFERENCES}

1. Vernon G, Feldman R, Wamalwa A. Refugees in primary care: from looking after to working together.

http://repository.forcedmigration.org/pdf/?pid=fmo .5929 (accessed 2 Dec 2010)

2. Launer J. Narrative-based Primary Care: a practical guide. Oxford: Radcliffe Medical Press, 2002.

DOI: 10.3399/bjgp11X549144

\title{
My life as a heartsink patient: living with chronic pain
}

I was like you once. Some patients would literally make my heart sink. Patients with chronic insoluble problems and their general misery often left me feeling exhausted. They seemed to come to clinic just to complain about how fed up they were. Then one day my life changed forever. After a ski trip I developed backache. When self-treatment failed I sought medical advice and ended up having surgery, which has left me with chronic pain. I have gone from being able to run, bike, and climb mountains to struggling with the stairs. There is some variation from day to day, but in the last 6 years there is not a day that I have not had some pain.

I have tried all the medical, psychological, and complementary therapies. None give me more than moderate relief and seemingly insignificant side effects are often as bad as my underlying symptoms. On good days I try and do more, but then spend 2 weeks in agony despite the strong opioids and other medications that I have to take every day. I am constipated, don't sleep, and have put on weight.

Unlike other forms of bereavement, I cannot move on as every day brings a fresh reminder of how awful my life is. I feel guilty that my wife has had to put up with this on a daily basis for 6 years and has given up so many of the things we used to do together. I feel guilty that my children are missing out on family activities due to my disability and worry that they will see my anger or frustration as their fault. I am angry about losing my well-paid career and only managing one and a half days a week with difficulty. But most of all I am just angry that no one can tell me why this has happened to me. I know I am not going to die from this, but I know that it is unlikely to get much better.

What I want from the doctors who treat me is this: sympathy, understanding of how my pain permeates every thread of my life, and honesty. The next time you see a heartsink patient remember this: once they were just like you. Imagine what it would be like to give up everything in your life that gives you pleasure. Our heartsink relationship is a product of my symptoms and your inability to help me. Conventional medical doctrine is that a sufficient knowledge base will allow you to heal. You pride yourself on being a healer and are uncomfortable when you cannot fulfil this role. Acknowledge this, act on it, and please don't just order more tests as a way to get patients out of the room.

\section{Name of author withheld}

DOI: 10.3399/bjgp11X549153 